TITLE:

\title{
Fatigue Properties of Borosilicate Glass Coated with Two-Layered Ceramic Thin Films
}

\section{$\operatorname{AUTHOR}(\mathrm{S}):$}

Hoshide, Toshihiko; Tanaka, Motoki; Tsujiai, Hideki

\section{CITATION:}

Hoshide, Toshihiko ...[et al]. Fatigue Properties of Borosilicate Glass Coated with TwoLayered Ceramic Thin Films. Journal of Materials Engineering and Performance 2013, 22(4): 1079-1084

ISSUE DATE:

2013-04

URL:

http://hdl.handle.net/2433/187070

RIGHT:

The final publication is available at link.springer.com 
Fatigue Properties of Borosilicate Glass Coated with Two-Layered Ceramic Thin Films

Toshihiko Hoshide ${ }^{1)}$, Motoki Tanaka ${ }^{2)}$ and Hideki Tsujiai ${ }^{2)}$

1) Department of Energy Conversion Science, Kyoto University, Kyoto 606-8501, Japan

2) Graduate School of Energy Science, Kyoto University, Kyoto 606-8501, Japan

\begin{abstract}
The long-term durability of ceramics coated glass with high performance should be appropriately evaluated prior to their applications. Fatigue properties of such materials should be clarified to ensure the long-term durability. In this work, a borosilicate glass was coated with single- and two-layered ceramic thin films by a sputtering method. Fatigue tests of coated glass were conducted under bending mode, and fatigue properties of coated glass were investigated. It was revealed that the fatigue life of glass coated with two-layered film became longer compared with those of glass substrate and glass coated single-layered film. Hardness as surface characteristics of coated films, and bending strength as bulk property of coated glass were correlated with the average fatigue life, though no good correlation was found between them. Fatigue resistance strength was proposed as another strength parameter. It was found that the average fatigue life was adequately expressed by a power function of fatigue resistance strength.
\end{abstract}

Keywords: Fatigue; coated glass; ceramic coating film; life distribution; bending strength; hardness, fatigue resistance strength

\title{
1. Introduction
}

Glass coated with ceramic materials is applicable to various engineering apparatuses. Recent works reported that glass coated with ceramic thin films by sputtering is functionally used as magnetic/electronic device materials (Ref 1-3) as well as optical ones (Ref 1, 4-7). In functional and/or mechanical applications of coated glass materials, their mechanical properties should be clarified for design to prevent their failure. The authors and their co-workers have investigated static mechanical properties, such as hardness and bending strength, of glass coated with single-layered and two-layered ceramic films (Ref 8-11). In practical application, however, it should be also considered that coated glass materials suffer fatigue damages due to cyclic thermal and/or mechanical stresses. Consequently, for improvement of the long-term durability in their practical applications, the structural design of systems using coated glass materials requires a good understanding of their fatigue properties. From this aspect, the authors revealed fundamental fatigue property of glass coated with single-layered ceramic film (Ref 12), though fatigue properties of two-layer film coated glass are unknown at present.

In the present work, a borosilicate glass was coated with two-layered ceramic films, which were produced by sputtering alumina $\left(\mathrm{Al}_{2} \mathrm{O}_{3}\right)$ and silicon carbide (SiC), and fatigue tests of the coated glass were conducted to clarify the fatigue life properties, which may depend on state or kind of coating film. Fatigue properties of the same glass material coated with $\mathrm{Al}_{2} \mathrm{O}_{3}$ or $\mathrm{SiC}$ single-layered film in a previous work (Ref 12) were also re-examined as comparative reference in this work. A radio-frequency (RF) magnetron sputtering method was adopted in producing thin ceramic films on glass. Coated glass materials were prepared by changing a combination of film materials and their thickness. Hardness of coating films and strength of coated glass were examined as static characteristics of coated glass. Axial loading tests, such as tensile tests, of brittle glass or ceramic materials are very difficult to be performed in evaluating their strength characteristics adequately (e.g. Ref 13). Therefore, 
static strength and fatigue tests were conducted under bending mode, instead of axial loading tests. Fatigue life distributions for various thicknesses of coated ceramic film were statistically discussed. It is convenient that fatigue characteristics obtained by long-time tests can be evaluated by using static strength properties given in short-time tests. In this work, the average fatigue life was correlated with some static strength parameters, and resultant correlations were discussed. Finally, a new strength parameter, "fatigue resistance strength," was proposed to get a better correlation with the average fatigue life.

\section{Experimental Procedures}

\subsection{Material processing}

A commercial borosilicate glass was used as a substrate material. The geometry of glass substrate was a disk type with a diameter of $100 \mathrm{~mm}$ and a thickness of $2 \mathrm{~mm}$. An oxide ceramics $\mathrm{Al}_{2} \mathrm{O}_{3}$ of $99.99 \%$ purity and a carbide ceramics $\mathrm{SiC}$ of $99.8 \%$ purity were selected as target materials. In the present work, $\mathrm{Al}_{2} \mathrm{O}_{3}$ or $\mathrm{SiC}$ film of single-layer was coated by sputtering procedure as mentioned below. Glass coated with single-layered ceramic film for tests to get static strength properties was prepared so that the film thickness $t_{\mathrm{f}}$ of single-layered ceramics should be $1 \mu \mathrm{m}, 3 \mu \mathrm{m}$ or $5 \mu \mathrm{m}$. In addition, glass coated with two-layered ceramic film was also produced for static and fatigue tests. In coating two-layered films, $\mathrm{Al}_{2} \mathrm{O}_{3}$ film was first coated on the substrate glass, and afterward $\mathrm{SiC}$ film was coated on $\mathrm{Al}_{2} \mathrm{O}_{3}$-coated glass. This layer order of coating films has an advantage in tribological aspect because $\mathrm{SiC}$ is harder than $\mathrm{Al}_{2} \mathrm{O}_{3}$. In two-layer coated glass, the thickness $t_{\mathrm{f}}$ of $\mathrm{Al}_{2} \mathrm{O}_{3}$ film as the first layer was set to be $3 \mu \mathrm{m}$, and $\mathrm{SiC}$ film in the second layer was coated to be $1 \mu \mathrm{m}, 3 \mu \mathrm{m}$ or $5 \mu \mathrm{m}$ in its thickness.

An RF magnetron sputtering apparatus of upper deposit type was used in the coating process. The distance between substrate and target material was fixed to be $40 \mathrm{~mm}$ in this apparatus. Substrate and target materials were being water-cooled during the processing to protect the materials from failure due to thermal deformation. Before starting a steady sputtering, pre-sputtering was carried out for 300 s so that a contaminated surface of target material could be removed. The initial degree of vacuum in a processing chamber was kept less than $1.3 \times 10^{-4} \mathrm{~Pa}$. The flow-rate and pressure of argon gas, which was used to activate the sputtering process in the chamber, was controlled to be $167 \mathrm{~mm}^{3} / \mathrm{s}$ and $1.3 \mathrm{~Pa}$, respectively. The initial temperature of substrate could be controlled, though the substrate temperature could not be controlled during sputtering of ceramic target materials. The initial temperature was set to be room temperature. The RF output power $P_{\mathrm{RF}}$ was set to be $P_{\mathrm{RF}}=600 \mathrm{~W}$.

Plate type specimens with dimensions of $10 \mathrm{~mm}$ in width and $40 \mathrm{~mm}$ in length were cut out from coated glass and the glass substrate itself for static and fatigue tests.

\subsection{Measurements of film hardness and bending strength}

The hardness of coated film is one of important factors in characterizing the strength of coated materials. To avoid the influence of the substrate hardness on the film hardness, a dynamic microhardness tester was adopted to measure the film hardness (Ref 10,11, 14).

Three-point bending tests with span length of $20 \mathrm{~mm}$ were conducted to evaluate the static bending strength of glass coated with single- and two-layered ceramics coated glass as well as glass substrate. The loading rate in bending test was controlled so that the rate of nominal stress at the position subjected to the maximum tensile stress in a specimen should be $100 \mathrm{MPa} / \mathrm{s}$. In setting a coated specimen on supporting equipment for bending, the coated surface of the specimen was located in the tensile side. All tests were carried out in an ambient atmosphere. 


\subsection{Procedures of fatigue tests}

Fatigue tests of ceramics coated glass and glass substrate and glass coated were conducted under three-point bending mode with a sinusoidal wave of $20 \mathrm{~Hz}$. The loading condition and the setting of specimens in fatigue tests were as the same as those in the static bending tests as mentioned in section 2.2. All fatigue tests were conducted in an ambient atmosphere.

The maximum stress $\sigma_{\max }$ generated in each specimen was controlled to be 70MPa or $80 \mathrm{MPa}$ during the fatigue tests. Theses maximum stress levels were selected to be lower than the lowest strength in static bending tests. A stress ratio $R$, which is defined as the ratio of minimum stress to maximum stress, was set to be 0.1 . Each fatigue test under $\sigma_{\max }=70 \mathrm{MPa}$ or $80 \mathrm{MPa}$ was stopped when one day (24 hours) passed without failure. A number of cycles at stopping fatigue test after 24 hours is $1.728 \times 10^{6}$ cycles .

\section{Experimental Results and Discussions}

\subsection{Static strength properties}

Table 1 presents static strength properties, i.e. average hardness $H_{\text {ave }}$ and average bending strength $\sigma_{\mathrm{f}, \text { ave }}$ of glass coated with single-layered ceramic film together with those of glass substrate. Table 2 summarizes hardness and bending strength of glass coated with two-layered ceramic films. The static strength properties of every coated glass are larger than respective properties of glass substrate. It is found that coating of ceramic films results in the improvement of static strength of glass. In each coated material, the hardness and strength become higher as the film thickness is increased. Table 1 reveals that SiC-coated glass is harder than $\mathrm{Al}_{2} \mathrm{O}_{3}$-coated one, though $\mathrm{SiC}$-coated glass is a little weaker than $\mathrm{Al}_{2} \mathrm{O}_{3}$-coated one. As seen in Tables 1 and 2, the hardest material is gained in glass coated with two-layered ceramic films.

\subsection{Fatigue properties}

\section{(1) Fatigue life characteristics in stress- life relations}

Figures 1(a) and (b) show variations of fatigue life $N_{\mathrm{f}}$ of glass coated with two-layered films under $\sigma_{\max }=70 \mathrm{MPa}$ and $80 \mathrm{MPa}$ respectively. The number attached to the arrow in the figure presents the number of specimens surviving at the truncated number of cycles, i.e., $1.728 \times 10^{6}$ cycles. Obviously, the number of surviving specimens is larger under lower applied stress. Fatigue lives of glass coated with single-layered ceramic films as well as glass substrate, which were obtained in a previous work (Ref 12), are also plotted as reference. Concerning data of single-layered film coated glass plotted in Fig. 1, data of only glass coated with $\mathrm{Al}_{2} \mathrm{O}_{3}$ film of $3 \mu \mathrm{m}$ thickness and $\mathrm{SiC}$ films of $1 \mu \mathrm{m}, 3 \mu \mathrm{m}$ and $5 \mu \mathrm{m}$ thickness are presented to avoid a complication in plotting. The $\mathrm{Al}_{2} \mathrm{O}_{3}$ and $\mathrm{SiC}$ films of the thickness specified as above were respectively selected as the first and second layers in glass coated with two-layered films. Fatigue lives of glass coated with single-layered SiC films are depicted with small marks.

As seen in Fig. 1, the life distribution of specimens broken during fatigue tests of every material has a large dispersion, similarly to such a scatter as observed in static strength of ceramics. It is seen that, comparing with fatigue lives of glass substrate, lives of glass coated with each ceramic film shift toward longer life region. In glass coated with SiC single- and $\mathrm{Al}_{2} \mathrm{O}_{3}$-SiC two-layered films, lower lives are observed than those of $\mathrm{Al}_{2} \mathrm{O}_{3}$ coated glass. When fatigue lives of glass coated with single-layered $\mathrm{SiC}$ film and two-layered $\mathrm{Al}_{2} \mathrm{O}_{3}-\mathrm{SiC}$ film are compared for the same thickness of SiC coated film, fatigue lives of glass coated with two-layered film shift toward longer life region as a whole trend. This implies that inserting $\mathrm{Al}_{2} \mathrm{O}_{3}$ film as the first layer results in improvement of fatigue life. 
Figure 2 shows the average fatigue life $N_{\text {f,ave }}$ correlated with the total film thickness. In glass coated with two-layered ceramic film, the total thickness is identical to the sum of $\mathrm{Al}_{2} \mathrm{O}_{3}$ and SiC film thickness. It is seen that the average lives of single-layered film coated glass are longer than that of glass substrate under $\sigma_{\max }=70 \mathrm{MPa}$ and $80 \mathrm{MPa}$. As a whole trend, the average fatigue life in glass coated with single-layered film seems to become longer in materials coated with thicker films, though its variation is small under $\sigma_{\max }=70 \mathrm{MPa}$. Two dotted curves drawn in Fig. 2 are the relations approximated by fitting data of glass substrate and glass coated with single-layered film to polynomial expression, for the respective applied maximum stresses $\sigma_{\max }=70 \mathrm{MPa}$ and $80 \mathrm{MPa}$. Although the average fatigue lives of glass coated with two-layered film coincide with the relation approximated for the other materials under $\sigma_{\max }=80 \mathrm{MPa}$, they are lower than the relation expected from the approximation for glass coated with single-layered film under $\sigma_{\max }=70 \mathrm{MPa}$.

In the following, statistical aspects of fatigue life characteristics are discussed. Statistical parameters related with fatigue life are summarized in Tables 3, 4 and 5 . In addition to the

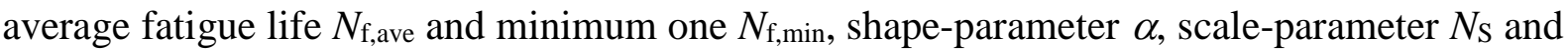
location-parameter $N_{\mathrm{L}}$ are also listed in the tables. These parameters are given by fitting respective cumulative probability-function $F\left(N_{\mathrm{f}}\right)$ of fatigue life $N_{\mathrm{f}}$ in experiments to three-parameter Weibull distribution function $F\left(N_{\mathrm{f}}\right)$, i.e.,

$$
F\left(N_{\mathrm{f}}\right)=1-\exp \left[-\left(\frac{N_{\mathrm{f}}-N_{\mathrm{L}}}{N_{\mathrm{S}}}\right)^{\alpha}\right]
$$

Most of all results shown in Tables 3, 4 and 5 are adequately expressed by Eq. (1). As seen in Tables 4 and 5, however, the location-parameters are zero in two life distributions obtained under $\sigma_{\max }=70 \mathrm{MPa}$ especially. These life distributions cannot be fitted to Eq. (1). Since two-parameter Weibull distribution function is given by setting $N_{\mathrm{L}}=0$ in Eq. (1), these life distributions are more adequately fitted to two-parameter Weibull distribution functions. Non-zero location parameter $N_{\mathrm{L}}$ in Eq. (1) corresponds to the minimum life expected in the fitted life distribution. Now, compare observed minimum fatigue lives with location parameters having non-zero values in Tables 4, 5 and 6. Most of location parameters are less than the minimum fatigue lives. This suggests that the location parameter gives a conservative estimation for the minimum fatigue life.

\section{(2) Correlations of average fatigue life with some parameters}

In this section, the average fatigue life $N_{\mathrm{f} \text {,ave }}$ is focused on as one of representative parameters in fatigue life distribution. In the following, the average fatigue life is correlated with some static parameters, which can be obtained rapidly and easily in experiments.

At first, the average fatigue life is correlated with the average hardness $H_{\text {ave }}$ in Fig. 3. The dotted straight lines in Fig. 3 indicate power functions of $H_{\text {ave }}$ fitted to average fatigue lives of glass substrate and glass coated with single-layered film for respective two levels of $\sigma_{\text {max }}$. Secondarily, the average fatigue life is correlated with the average bending strength $\sigma_{\mathrm{f}, \mathrm{ave}}$ in Fig. 4 . The dotted straight lines in Fig. 4 express the relations of $N_{\mathrm{f} \text {,ave }}$ of glass substrate and glass coated with single-layered film, which are approximated as power functions of $\sigma_{\mathrm{f} \text {,ave }}$ for respective two levels of $\sigma_{\max }$. By comparison of results depicted in Figs. 3 and 4, it is seen that the average fatigue life of glass coated with two-layered film can be more appropriately expressed by the relation with the average bending strength, though the two approximated relations for $\sigma_{\max }=70 \mathrm{MPa}$ and $80 \mathrm{MPa}$ are separated each other as a matter of course. 
In this work, a new strength parameter was proposed to correlate the average fatigue life. The parameter was designated as fatigue resistance strength $S_{\text {res}}$, and it was defined as the average bending strength $\sigma_{\text {f,ave }}$ divided by the applied maximum stress $\sigma_{\max }$; i.e.

$S_{\text {res }} \equiv\left(\sigma_{\mathrm{f}, \mathrm{ave}} / \sigma_{\mathrm{max}}\right)$

Figure 5 presents the relation between average fatigue lives and fatigue resistance strength. As seen in the figure, almost all of average fatigue lives are expressed by a power function of the fatigue resistance strength, irrespective of film material and maximum stress applied in fatigue tests. The straight solid line in Fig. 5 expresses a power function expressed as;

$N_{\text {f,ave }}=5.15 \times 10^{3}\left(S_{\text {res }}\right)^{15.7}$

Equation (3) is obtained by the best fitting for the results of glass substrate and glass coated with single-layered film. In Fig. 5, two dotted lines are also drawn to show a scatter band of a factor of two. By using the fatigue resistance strength, the average fatigue life of glass coated with two-layered film is almost estimated within the scatter range of a factor of two.

\section{Conclusions}

The long-term durability of ceramics coated glass with high performance should be adequately evaluated prior to their application. This work was done to aim at clarifying fatigue properties as the long-term durability of such materials.

In the present work, a borosilicate glass was coated with ceramic thin films by a radio-frequency (RF) magnetron sputtering method. Alumina $\left(\mathrm{Al}_{2} \mathrm{O}_{3}\right)$ and silicon carbide (SiC) were adopted as coating film materials. Fatigue properties of glass coated with ceramic thin films were investigated. Under RF output power of $600 \mathrm{~W}$, the thickness $t_{\mathrm{f}}$ of coated film was prepared to be $1 \mu \mathrm{m}, 3 \mu \mathrm{m}$ or $5 \mu \mathrm{m}$ for glass coated with single-layered film, and glass coated with two-layered $\mathrm{Al}_{2} \mathrm{O}_{3}$-SiC film was also produced. In producing glass coated with two-layered film, the thickness $t_{\mathrm{f}}$ of $\mathrm{Al}_{2} \mathrm{O}_{3}$ film as the first layer was set to be $3 \mu \mathrm{m}$, and $t_{\mathrm{f}}$ of $\mathrm{SiC}$ film as the second layer was changed to be $1 \mu \mathrm{m}, 3 \mu \mathrm{m}$ or $5 \mu \mathrm{m}$. As static strength properties, hardness of coated ceramic films was measured and the static strength of coated glass was evaluated under three-point bending mode. As a whole trend, the hardness and bending strength became higher with increasing film thickness.

Fatigue tests of coated glass were conducted under three-point bending mode and at stress ratio of 0.1 . It was clarified that the fatigue life distribution of glass coated with two-layered $\mathrm{Al}_{2} \mathrm{O}_{3}$-SiC film was found to shift toward longer life region compared with that of glass coated with single-layered SiC film. Most of fatigue life distributions were able to be fitted by using three parameter Weibull distribution functions. The average fatigue life of every coated glass was correlated with the average hardness and strength. However, no good correlation of the average fatigue life was observed with these parameters. Another strength parameter, i.e. fatigue resistance strength, which was defined as the average bending strength divided by the maximum applied stress, was adopted, and correlated with the average fatigue life. It was found that the average fatigue life was adequately expressed as a power function of the fatigue resistance strength, irrespective of film material kind and applied fatigue stress.

\section{References}

1. K.H. Kim, K.C. Park and D.Y. Ma, Structural, Electrical and Optical Properties of Aluminum Doped Zinc Oxide Films Prepared by Radio Frequency Magnetron Sputtering, J Appl Phys, 1997, 81, p 7764-7772 
2. Y. Fukuma, H. Asada, N. Nishimura and T. Koyanagi, Ferromagnetic Properties of IV-VI Diluted Magnetic Semiconductor $\mathrm{Ge}_{1-\mathrm{x}} \mathrm{Mn}_{\mathrm{x}} \mathrm{Te}$ Films Prepared by Radio Frequency Sputtering, J Appl Phys, 2003, 93, p 4034-4039

3. Y. Peng, C. Park and D.E. Laughlin, $\mathrm{Fe}_{3} \mathrm{O}_{4}$ Thin Films Sputter Deposited from Iron Oxide Targets, J Appl Phys, 2003, 93, p 7657-7959

4. D.A. Chang, P. Lin and T.Y. Tseng, Optical Properties of $\mathrm{ZrTiO}_{4}$ Films Grown by Radio-Frequency Magnetron Sputtering, J Appl Phys, 1995, 77, p 4445-445 1

5. G.T. Kiehne, G.K.L. Wong and J.B. Ketterson, Optical Second-Harmonic Generation in Sputter-Deposited AlN Films, J Appl Phys, 1998, 84, p 5922-5927

6. H. Mizoguchi, N. Kitamura, K. Fukumi, T. Mihara, J. Nishii, M. Nakamura, N. Kikuchi, H. Hosono and H. Kawazoe, Optical Properties of $\mathrm{SrMoO}_{3}$ Thin Film, J Appl Phys, 2000, 87, p 4617-4619

7. S. Venkataraj, O. Kapperiz, H. Weis, R. Drese, R. Jayavel and M. Wuttig, Structural and Optical Properties of Thin Zirconium Oxide Films Prepared by Reactive Direct Current Magnetron Sputtering, J Appl Phys, 2002, 92, p 3599-3607

8. T. Hoshide and M. Hirano, Evaluation of Strength of Borosilicate Glass Coated with Ceramic Materials by Sputtering, J Mater Eng Perform, 2010, 19, p 562-567

9. T. Hoshide and T. Otomo, Mechanical Properties of Borosilicate Glass Coated with Two-layered Ceramics by Sputtering, J Mater Eng Perform, 2008, 17, p 91-97

10. T. Hoshide, A. Nebu and K. Hayashi, Bending Strength of Borosilicate Glass Coated with Alumina and Silicon Carbide by RF Magnetron Sputtering, JSME Int J, Ser A, 1998, 41, p 332-337

11. T. Hoshide, K. Hayashi, T. Saito, K. Katsuki and T. Inoue, Mechanical Properties of Borosilicate Glass Coated with Alumina by Sputtering Process, Mater Sci Res Int, 1996, 2, p 33-38

12. T. Hoshide and M. Tanaka, Fatigue Properties of Borosilicate Glass Coated with Ceramics and Effect of Proof testing on Life Distribution, Procedia Eng, 2011, 10, p 740-745

13. T. Hoshide, Strength Characteristics of Structural Ceramics, Mater Sci Res Int, 1996, 2, p 220-228

14. P.J. Burnett and D.S. Rickerby, Assessment of Coating Hardness, Surface Eng, 1987, 3, p 69-76 
Table 1 Static strength properties of glass coated with single-layered ceramic film

\begin{tabular}{|c|c|c|c|c|c|}
\hline \multirow{2}{*}{ Mechanical property } & \multicolumn{2}{|c|}{ Glass coated with single-layered ceramics } & \multirow{2}{*}{$\begin{array}{c}\text { Glass } \\
\text { substrate }\end{array}$} \\
\cline { 2 - 5 } & \multirow{2}{*}{$\begin{array}{c}\text { Film } \\
\text { material }\end{array}$} & \multicolumn{3}{|c|}{ Film thickness $t_{\mathrm{f}}$} & \\
\cline { 2 - 5 } $\begin{array}{c}\text { Average hardness } \\
H_{\text {ave }}\end{array}$ & $\mathrm{Al}_{2} \mathrm{O}_{3}$ & 314 & 338 & $36 \mathrm{~m}$ & \multirow{2}{*}{282} \\
\cline { 2 - 5 } & $\mathrm{SiC}$ & 345 & 369 & 390 & \\
\hline $\begin{array}{c}\text { Average bending } \\
\text { strength } \sigma_{\mathrm{f}, \text { ave }}\end{array}$ & $\mathrm{Al}_{2} \mathrm{O}_{3}$ & $97.2 \mathrm{MPa}$ & $99.4 \mathrm{MPa}$ & $99.5 \mathrm{MPa}$ & \multirow{2}{*}{$88.5 \mathrm{MPa}$} \\
\cline { 2 - 5 } & $\mathrm{SiC}$ & $91.9 \mathrm{MPa}$ & $96.6 \mathrm{MPa}$ & $98.6 \mathrm{MPa}$ & \\
\hline
\end{tabular}

Table 2 Static strength properties of glass coated with two-layered ceramic film

\begin{tabular}{|c|c|c|c|}
\hline Film material & \multicolumn{3}{|c|}{ SiC films coated on $\mathrm{Al}_{2} \mathrm{O}_{3}$ coated glass } \\
\hline $\mathrm{Al}_{2} \mathrm{O}_{3}$ film thickness $t_{\mathrm{f}}$ & \multicolumn{3}{|c|}{$3 \mu \mathrm{m}$} \\
\hline $\mathrm{SiC}$ film thickness $t_{\mathrm{f}}$ & $1 \mu \mathrm{m}$ & $3 \mu \mathrm{m}$ & $5 \mu \mathrm{m}$ \\
\hline Average hardness $H_{\text {ave }}$ & 472 & 469 & 524 \\
\hline $\begin{array}{c}\text { Average bending } \\
\text { strength } \sigma_{\mathrm{f}, \text { ave }}\end{array}$ & $93.5 \mathrm{MPa}$ & $96.9 \mathrm{MPa}$ & $107 \mathrm{MPa}$ \\
\hline
\end{tabular}

Table 3 Results in fatigue tests of glass substrate and $\mathrm{Al}_{2} \mathrm{O}_{3}$ single-film coated glass

\begin{tabular}{|c|c|c|c|c|}
\hline \multirow{2}{*}{ Material } & \multicolumn{2}{|c|}{ Glass substrate } & \multicolumn{2}{c|}{$\begin{array}{c}\text { Glass coated with } \\
\mathrm{Al}_{2} \mathrm{O}_{3} \text { film of } 3 \mu \mathrm{m}\end{array}$} \\
\hline Maximum stress $\sigma_{\max }$ & $70 \mathrm{MPa}$ & $80 \mathrm{MPa}$ & $70 \mathrm{MPa}$ & $80 \mathrm{MPa}$ \\
\hline Average fatigue life $N_{\mathrm{f}, \text { ave }}$ (cycles) & $3.44 \times 10^{5}$ & $6.49 \times 10^{3}$ & $2.61 \times 10^{5}$ & $1.16 \times 10^{5}$ \\
\hline Minimum fatigue life $N_{\mathrm{f} \text {,min }}$ (cycles) & 169 & 41 & 1033 & 982 \\
\hline Shape parameter $\alpha$ & 0.41 & 0.43 & 0.35 & 0.39 \\
\hline Scale parameter $N_{\mathrm{S}}($ cycles) & $1.62 \times 10^{5}$ & $7.82 \times 10^{2}$ & $9.74 \times 10^{4}$ & $3.67 \times 10^{4}$ \\
\hline Location Parameter $N_{\mathrm{L}}$ (cycles) & 5 & 41 & 978 & 963 \\
\hline
\end{tabular}

Table 4 Results in fatigue tests of SiC single-film coated glass

\begin{tabular}{|c|c|c|c|c|c|c|}
\hline Film thickness $t_{\mathrm{f}}$ & \multicolumn{2}{|c|}{$1 \mu \mathrm{m}$} & \multicolumn{2}{c|}{$3 \mu \mathrm{m}$} & \multicolumn{2}{c|}{$5 \mu \mathrm{m}$} \\
\hline $\begin{array}{c}\text { Maximum applied } \\
\text { stress } \sigma_{\max }\end{array}$ & $70 \mathrm{MPa}$ & $80 \mathrm{MPa}$ & $70 \mathrm{MPa}$ & $80 \mathrm{MPa}$ & $70 \mathrm{MPa}$ & $80 \mathrm{MPa}$ \\
\hline $\begin{array}{c}\text { Average fatigue life } \\
N_{\mathrm{f}, \text { ave }} \text { (cycles) }\end{array}$ & $1.85 \times 10^{5}$ & $2.48 \times 10^{4}$ & $3.08 \times 10^{5}$ & $9.17 \times 10^{4}$ & $1.35 \times 10^{5}$ & $3.36 \times 10^{5}$ \\
\hline $\begin{array}{c}\text { Minimum fatigue life } \\
N_{\mathrm{f}, \mathrm{min}}(\mathrm{cycles})\end{array}$ & 314 & 47 & 433 & 111 & 1546 & 145 \\
\hline Shape parameter $\alpha$ & 0.49 & 0.30 & 0.41 & 0.36 & 0.51 & 0.28 \\
\hline $\begin{array}{c}\text { Scale parameter } N_{\mathrm{S}} \\
\text { (cycles) }\end{array}$ & $1.20 \times 10^{5}$ & $2.52 \times 10^{3}$ & $1.65 \times 10^{5}$ & $3.65 \times 10^{4}$ & $8.62 \times 10^{4}$ & $1.08 \times 10^{5}$ \\
\hline $\begin{array}{c}\text { Location Parameter } \\
N_{\mathrm{L}} \text { (cycles) }\end{array}$ & 0 & 47 & 65 & 99 & 1250 & 121 \\
\hline
\end{tabular}


Table 5 Results in fatigue tests of two-layered films coated glass

\begin{tabular}{|c|c|c|c|c|c|c|}
\hline $\mathrm{Al}_{2} \mathrm{O}_{3}$ film thickness $t_{\mathrm{f}}$ & \multicolumn{5}{|c|}{$3 \mu \mathrm{m}$} \\
\hline SiC film thickness $t_{\mathrm{f}}$ & \multicolumn{2}{|c|}{$1 \mu \mathrm{m}$} & \multicolumn{2}{c|}{$3 \mu \mathrm{m}$} & \multicolumn{2}{c|}{$5 \mu \mathrm{m}$} \\
\hline $\begin{array}{c}\text { Maximum applied } \\
\text { stress } \sigma_{\max }\end{array}$ & $70 \mathrm{MPa}$ & $80 \mathrm{MPa}$ & $70 \mathrm{MPa}$ & $80 \mathrm{MPa}$ & $70 \mathrm{MPa}$ & $80 \mathrm{MPa}$ \\
\hline $\begin{array}{c}\text { Average fatigue life } \\
N_{\mathrm{f}, \text { ave }} \text { (cycles) }\end{array}$ & $1.66 \times 10^{5}$ & $2.85 \times 10^{4}$ & $1.62 \times 10^{5}$ & $1.20 \times 10^{5}$ & $2.86 \times 10^{5}$ & $2.33 \times 10^{5}$ \\
\hline $\begin{array}{c}\text { Minimum fatigue life } \\
N_{\mathrm{f}, \text { min }} \text { (cycles) }\end{array}$ & 383 & 94 & 322 & 990 & 1289 & 1070 \\
\hline Shape parameter $\alpha$ & 0.40 & 0.35 & 0.39 & 0.34 & 0.53 & 0.39 \\
\hline $\begin{array}{c}\text { Scale parameter } N_{\mathrm{S}} \\
\text { (cycles) }\end{array}$ & $4.28 \times 10^{4}$ & $1.19 \times 10^{4}$ & $8.40 \times 10^{4}$ & $4.05 \times 10^{4}$ & $1.92 \times 10^{5}$ & $1.10 \times 10^{5}$ \\
\hline $\begin{array}{c}\text { Location Parameter } N_{\mathrm{L}} \\
\text { (cycles) }\end{array}$ & 367 & 87 & 125 & 972 & 0 & 910 \\
\hline
\end{tabular}

(a) $\sigma_{\max }=70 \mathrm{MPa}$

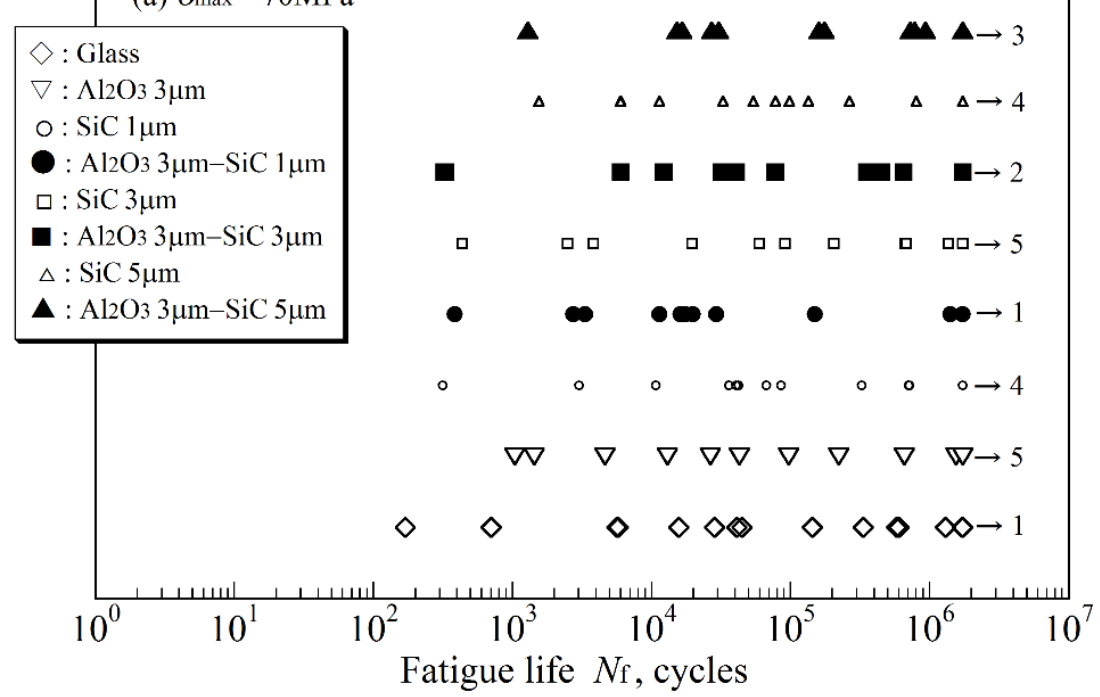

(b) $\sigma_{\text {max }}=80 \mathrm{MPa}$

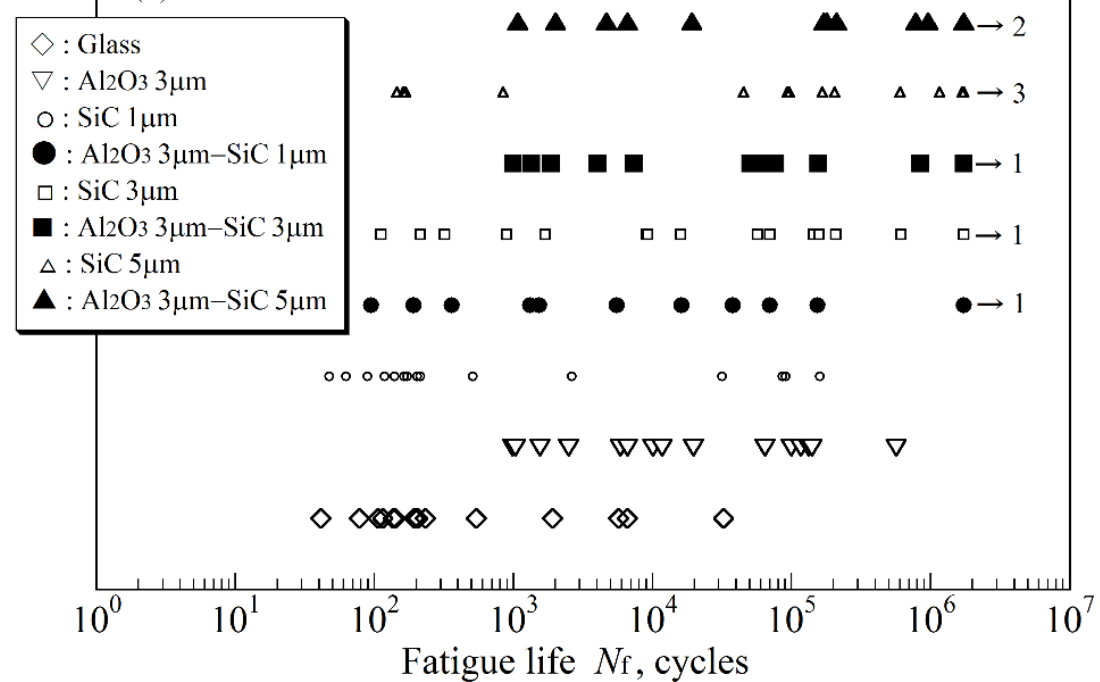

Fig. 1 Fatigue life of coated glass; (a) $\sigma_{\max }=70 \mathrm{MPa}$, (b) $\sigma_{\max }=80 \mathrm{MPa}$ 


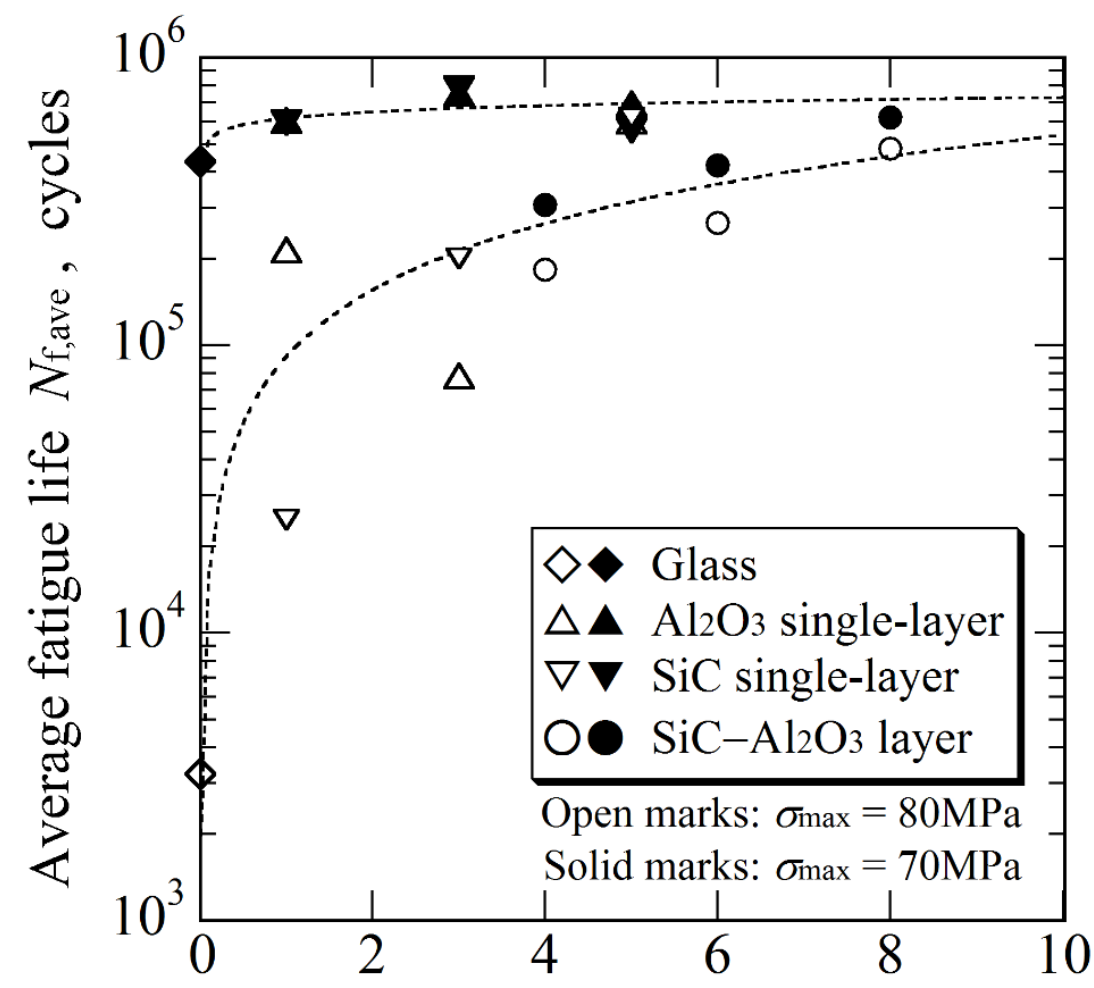

Total thickness of coated film $t \mathrm{f}, \mu \mathrm{m}$

Fig. 2 Relation between mean fatigue correlated and total thickness of coated film

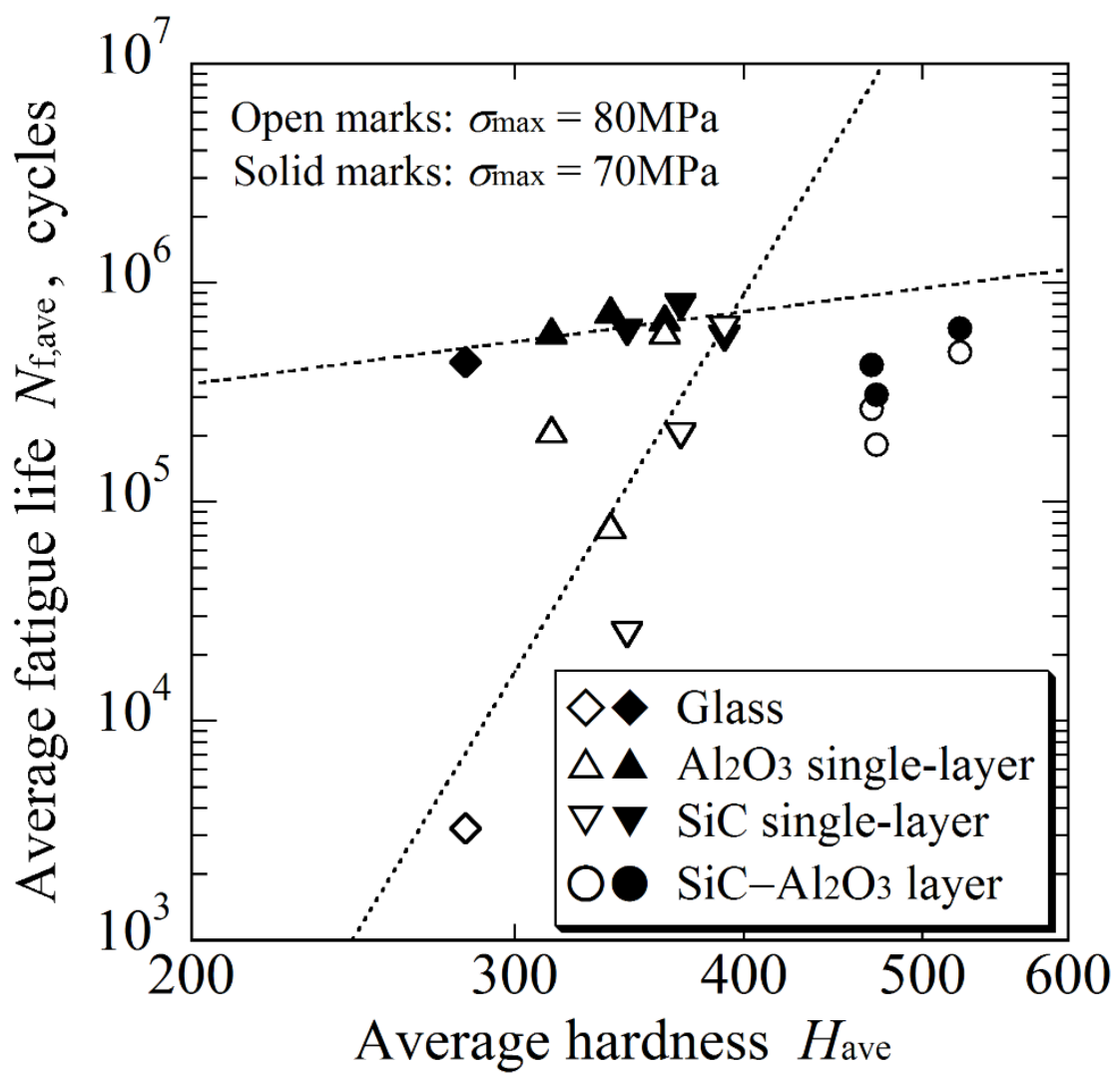

Fig. 3 Average fatigue life correlated with average hardness 


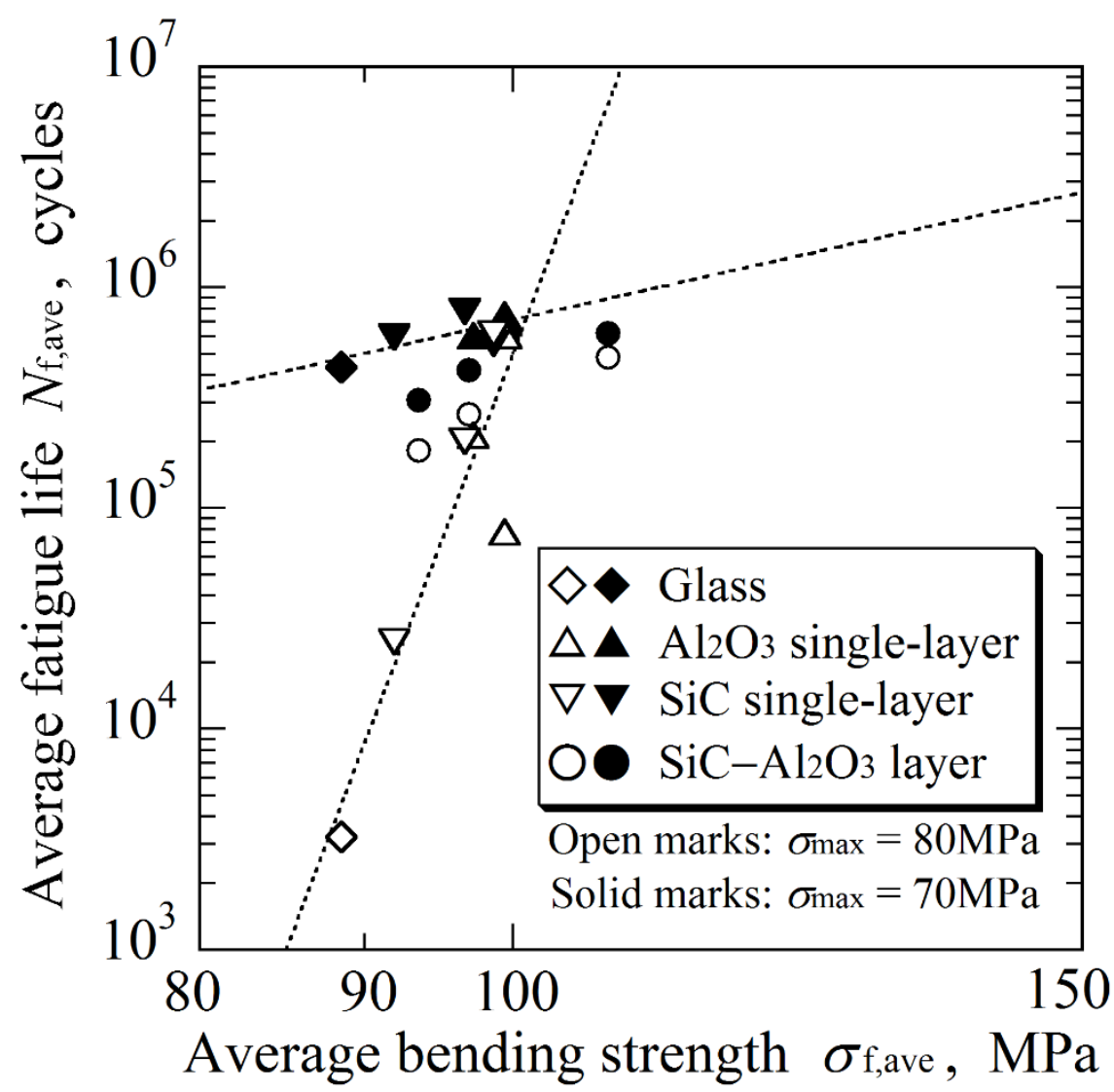

Fig. 4 Average fatigue life correlated with average bending strength

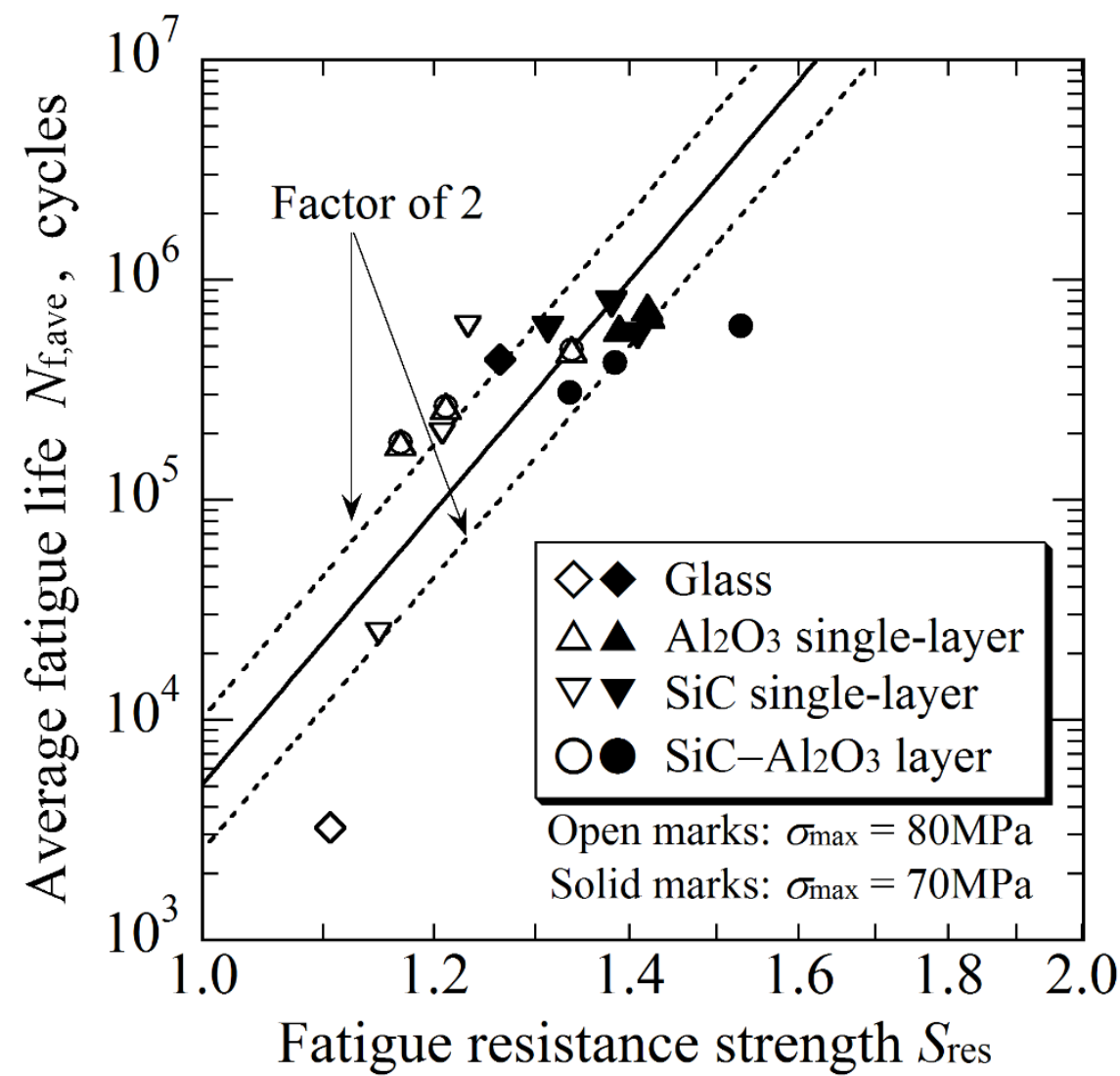

Fig. 5 Average fatigue life correlated with fatigue resistance strength 